\title{
Concentration and Preservation of Very Low Abundance Biomarkers in Urine, such as Human Growth Hormone (hGH), by Cibacron Blue F3G-A Loaded Hydrogel Particles
}

\author{
Claudia Fredolini ${ }^{1,2,5, \uparrow}$, Francesco Meani ${ }^{3,5, \dagger}$, K. Alex Reeder ${ }^{5}$, Sally Rucker ${ }^{5}$, Alexis Patanarut ${ }^{6}$, Palma J. \\ Bottere ${ }^{6}{ }^{6}$, Barney Bishop ${ }^{6}$, Caterina Longo ${ }^{4,5}$, Virginia Espina ${ }^{5}$, Emanuel F. Petricoin III $^{5}$, Lance A. Liotta ${ }^{5}$, and \\ Alessandra Luchini ${ }^{5}(\square)$ \\ ${ }^{1}$ Department of Urology, S. Giovanni Bosco Hospital, Torino 10154, Italy \\ ${ }^{2}$ Department of Medicine and Experimental Oncology, University of Turin, Turin 10126, Italy \\ ${ }^{3}$ Gynecology and Obstetrics Department, University of Brescia, Brescia 25100, Italy \\ ${ }^{4}$ Department of Dermatology and Venereology, University of Modena and Reggio Emilia, Modena 41100, Italy \\ ${ }^{5}$ Center for the Applied Proteomics and Molecular Medicine, George Mason University, Manassas, VA 20110, USA \\ ${ }^{6}$ Chemistry and Biochemistry Department, George Mason University, Manassas, VA 20110, USA. \\ Received: 17 September 2008 / Revised: 6 November 2008 / Accepted: 7 November 2008 \\ CTsinghua Press and Springer-Verlag 2008. This article is published with open access at Springerlink.com
}

\begin{abstract}
Urine is a potential source of diagnostic biomarkers for detection of diseases, and is a very attractive means of non-invasive biospecimen collection. Nonetheless, proteomic measurement in urine is very challenging because diagnostic biomarkers exist in very low concentration (usually below the sensitivity of common immunoassays) and may be subject to rapid degradation. Hydrogel nanoparticles functionalized with Cibacron Blue F3G-A (CB) have been applied to address these challenges for urine biomarker measurement. We chose one of the most difficult low abundance, but medically relevant, hormones in the urine: human growth hormone (hGH). The normal range of hGH in serum is 1 to $10 \mathrm{ng} / \mathrm{mL}$ but the urine concentration is suspected to be a thousand times less, well below the detection limit $(50 \mathrm{pg} / \mathrm{mL})$ of sensitive clinical hGH immunoassays. We demonstrate that $\mathrm{CB}$ particles can capture, preserve and concentrate hGH in urine at physiological salt and urea concentrations, so that hGH can be measured in the linear range of a clinical immunometric assay. Recombinant and cadaveric hGH were captured from synthetic and human urine, concentrated and measured with an Immulite chemiluminescent immunoassay. Values of hGH less than $0.05 \mathrm{ng} / \mathrm{mL}$ (the Immulite detection limit) were concentrated to $2 \mathrm{ng} / \mathrm{mL}$, with a urine volume of $1 \mathrm{~mL}$. Dose response studies using $10 \mathrm{~mL}$ of urine demonstrated that the concentration of hGH in the particle eluate was linearly dependent on the concentration of hGH in the starting solution, and that all hGH was removed from solution. Thus if the starting urine volume is $100 \mathrm{~mL}$, the detection limit will be $0.1 \mathrm{pg} / \mathrm{mL}$. Urine from a healthy donor whose serum $\mathrm{hGH}$ concentration was $1.34 \mathrm{ng} / \mathrm{mL}$ was studied in order detect endogenous $\mathrm{hGH}$. Starting from a volume of $33 \mathrm{~mL}$, the particle eluate had an hGH concentration of $58 \mathrm{pg} / \mathrm{mL}$, giving an estimated initial concentration of hGH in urine of 0.175 $\mathrm{pg} / \mathrm{mL}$. The nanotechnology described here appears to have the desired precision, accuracy and sensitivity to support large scale clinical studies of urine hGH levels.
\end{abstract}

Address correspondence to aluchini@gmu.edu

${ }^{\dagger}$ These authors equally contributed to this work. 


\section{KEYWORDS}

Urine proteomics, Cibacron Blue F3G-A, human growth hormone, hydrogel nanoparticles, $\mathrm{N}$-isopropylacrylamide

\section{Introduction}

Urine is a biological fluid produced by the kidney through a process of blood filtration, reabsorption and tubular secretion. Although it is predominantly composed of waste products, it may contain a vast amount of biological information useful for diagnostic purposes and is a mirror of physiopathological urogenital and systemic conditions [1].

Urine is an ideal biological fluid for clinical analysis because the collection is simple, economic, and non-invasive, and large quantities of sample are available. For these reasons it has been proposed as an alternative to blood collection (venipuncture), if not as a diagnostic tool, at least as a screening test used to determine which subjects should undergo serum analysis. Nevertheless, the very low concentration of many molecules of interest in urine, and the presence of different interfering substances, have hampered the development of urine-based diagnostics tests, as well as the discovery of novel clinically useful biomarkers. The recent application of modern proteomic technologies and approaches to urine have led to the discovery of hundreds of proteins as new potential biomarkers of disease $[2,3]$. The existence of these potential urine disease biomarkers has paradoxically highlighted the weakness of urine as a diagnostic fluid: (1) the total protein concentration of urine is highly variable from hour to hour depending on the hydration state and the kidney function; (2) the size range and composition of proteins normally entering the urine is a function of glomerular filtration and is not simply proportional to the blood concentration of a given biomarker; (3) diagnostic biomarkers may exist in very low concentrations in the urine (the concentration of many blood biomarkers may be one hundred to one thousand times less than that in the blood, such that the marker is undetectable by a conventional clinical assay); (4) urine biomarkers may be highly labile and subject to degradation. Thus there is a great clinical need to create new tools that will selectively concentrate and preserve low abundance peptides and proteins in the urine [2-4].

Nanomedicine, the application of nanotechnology to the medical field [5], offers a potential means of overcoming the above drawbacks of urine. Nanoparticles provide a new medium for the selective concentration and uptake of urine biomarkers. Many classes of nanoparticles (such as quantum dots, gold nanoparticles, magnetic nanoparticles, and hydrogels) have been proposed to be applicable in diagnosis, monitoring, and treatment of disease [6]. Among known nanoparticles, hydrogel particles offer a simple means to capture, concentrate and preserve urinary proteins of interest.

Hydrogel particles are submicron spheres obtained via polymerization of water soluble monomers, and consist of swollen three-dimensional networked structures in which water is the major component. The size of the particles can change in response to a variety of stimuli, such as temperature, $\mathrm{pH}$, ionic strength, light and electric fields [7-13]. Because of their physicochemical properties and their open structure, hydrogel particles offer an effective means to encapsulate target analytes in solution. Because of their swelling and de-swelling properties in response to mild modifications of the solution and their ability to be functionalized with different chemical moieties, they have been extensively investigated as targeted drug delivery systems [14, 15].

Recently we demonstrated the ability of poly $(\mathrm{N}$ isopropylacrylamide) (NIPAm) based hydrogel particles to rapidly capture and concentrate low molecular weight (LMW) and low abundance proteins from a complex protein solution such as serum, and preserve the captured analytes from degradation [16]. Their particle porosity is ideal for size selection of proteins, especially the LMW proteins and peptides that are likely to be passed into the urine. A variety of chemical ligands that act as affinity baits have been incorporated in the

\section{Springer}


NIPAm based particles (e.g., acrylic acid, allylamine, $p$-vinylphenylboronic acid [17], $N$-acryoyl-maminophenylboronic acid [18], cyclodextrins, and triazinyl dyes). The baits can be designed to sequester specific classes of proteins or metabolites, thereby increasing the affinity between the particles and the analytes.

In this study we have applied this new class of harvesting nanoparticles to urine samples. In order to give proof of concept, we chose one of the most difficult low abundance, but medically relevant, hormones present in urine: human growth hormone (hGH). In fact hGH is currently undetectable in urine when measured by the most sensitive clinical assay used for measuring hGH in serum $[19,20]$. Human growth hormone is a peptide hormone of 191 amino acids secreted by somatotroph cells of the pituitary gland in a pulsatile pattern under hypothalamic control [21, 22]. Its secretion is influenced by several physiological and pathophysiological conditions such as gender, age, sleep, fever, physical exercise, nutritional state and other metabolic factors. As a result, hGH levels in blood fluctuate widely. In humans, hGH levels reach $50-100 \mathrm{ng} / \mathrm{mL}$ at peak and fall below $0.03 \mathrm{ng} / \mathrm{mL}$ at nadir [19]. Blood contains multiple hGH isoforms $(22,20$, and $17 \mathrm{kDa})$, with the $22 \mathrm{kDa}$ form being the most abundant $[23,24]$. The principal metabolic clearance of hGH proceeds through glomerular filtration, reabsorption and degradation in proximal tubular cells. This clearance process is very efficient, with only a very minute amount of filtrated hGH $(<0.01 \%)$ reaching the final urine volume [19]. Several previous studies have shown that-given an intact renal function-hGH concentration in urine, although much lower than in serum (between one hundred to one thousand times less than that in blood - in the low $\mathrm{pg} / \mathrm{mL}$ range $[25,26])$ reflects its physiological secretion.

Determination of hGH levels is a key tool for the clinical management of hGH secretion disorders: childhood and adulthood insufficiency or overproduction. Accurate, universally valid and convenient hGH measurements in urine are highly desirable but, for many reasons, this goal remains elusive [19,
20]. Many efforts have been made to detect hGH in urine, both for clinical and anti-doping purposes using different classes of immunologic assays (e.g., NordiTest U-hGH assay and Nichols Institute Chemoluminescence uGH immunoassay) [27, 28] but the very low concentration of the hormone in urine, complexity of the assays, and high costs involved have hindered clinical urine test development. Assessment of nonphysiological levels of hGH still relies on time consuming, expensive and potentially hazardous tests, such as repetitive blood measurement or dynamic (stimulating or suppressive) tests. In order to overcome the drawbacks of current methods of hGH testing in urine, we synthesized hydrogel NIPAm nanoparticles incorporating a Cibacron Blue dye bait. Cibacron Blue F3G-A (CB) is a monochlorotriazinyl textile dye, containing an antraquinone chromophore. It is widely used as a ligand, coupled to numerous matrices, in affinity chromatography because of its well known ability to interact with proteins $[29,30]$. Recently the ability of CB to interact with recombinant hGH has been demonstrated [31, 32].

In this study we demonstrate that this novel nanotechnology is able to capture, preserve and concentrate hGH in urine so that hGH can be determined in the linear range of a clinical immunometric assay (Immulite-Siemens Medical Solution Diagnostic), as depicted in Fig. 1. These particles capture all of the hGH in the bulk fluid of the urine, and since the protein is then collected in a small volume the concentration of hGH is significantly increased.

The harvesting particles we describe are not specific to the case study we chose, hGH, but also have the capability to capture, concentrate and protect from degradation other classes of low molecular weight medically relevant protein biomarkers in urine. In order to prove the non-specificity of the harvesting particles, capture of interleukin 8 (IL-8) was investigated. IL-8 is a chemokine involved in proinflammatory and proangiogenic processes, the increased concentration of which in the urine of non-Hodgkin's Lymphoma patients was recently reported [33]. 

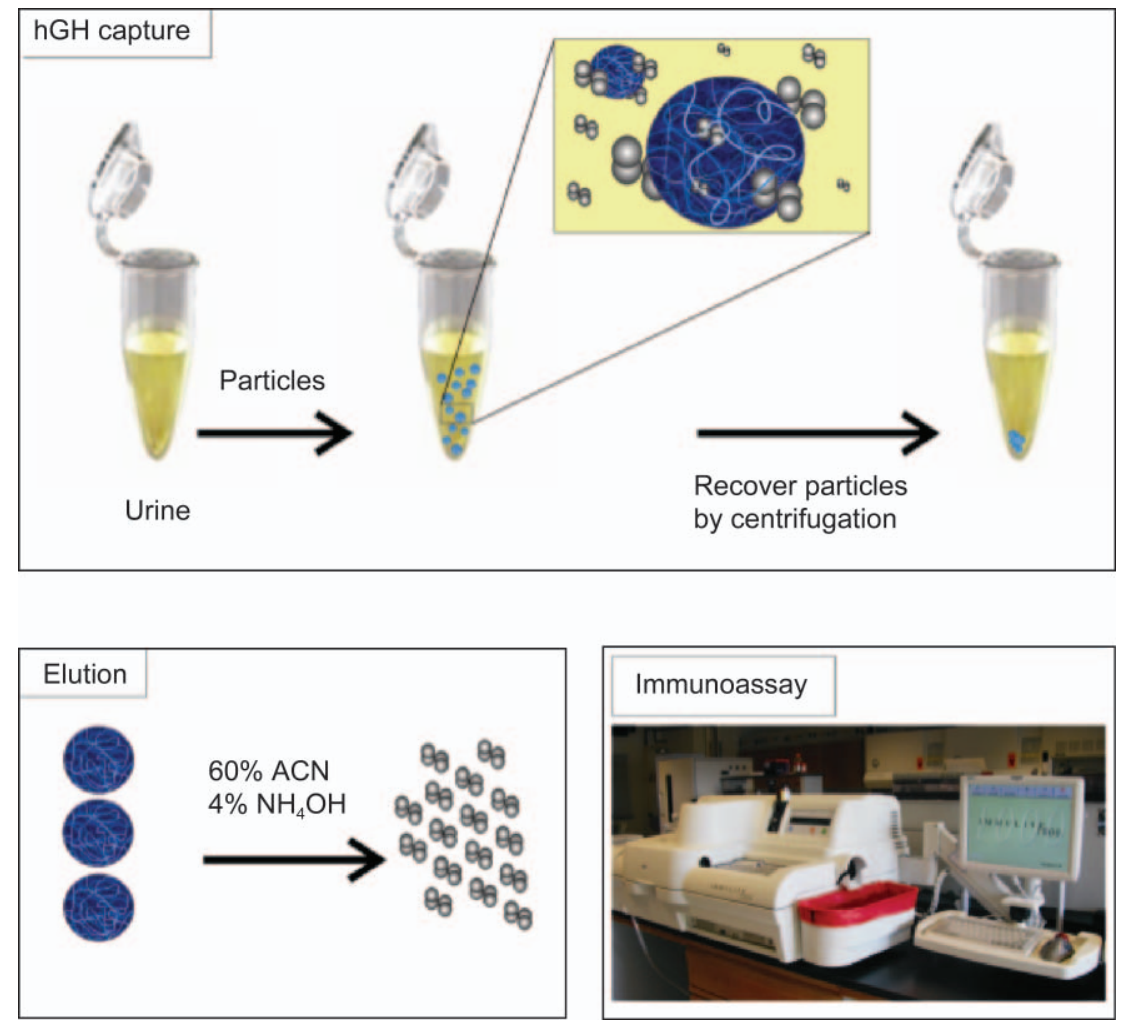

Figure 1 Amplification strategy for immunological detection of human growth hormone $(\mathrm{hGH})$ in urine. Particles are mixed with urine, subsequently capture hGH, and are separated via centrifugation. Elution of $\mathrm{hGH}$ from particles is performed with an acetonitrile (ACN)$\mathrm{NH}_{4} \mathrm{OH}$ buffer. Immunoassay is performed on $\mathrm{hGH}$ eluted from the particles
1.2 Synthesis and characterization of hydrogel nanoparticles

NIPAm/AA particles were prepared containing specific percentages of AA with respect to the total monomer ( $5 \%$ or $10 \%$ ). NIPAm $(0.89 \mathrm{~g}, 7.83 \mathrm{mmol})$ and BIS (0.042 g, $0.27 \mathrm{mmol}$ ) were dissolved in $30 \mathrm{~mL}$ of $\mathrm{H}_{2} \mathrm{O}$ and then passed through a $0.2 \mathrm{~m}$ filter nylon membrane. The solution was purged with nitrogen for $15 \mathrm{~min}$ at room temperature with a medium stirring rate before AA $(0.026 \mathrm{~g}$, $0.45 \mathrm{mmol}$ for $5 \%$ loaded particles and $0.051 \mathrm{~g}, 0.90 \mathrm{mmol}$ for $10 \% \mathrm{AA}$ loaded particles) was added. The solution was purged with nitrogen for another $15 \mathrm{~min}$ and then heated to $75{ }^{\circ} \mathrm{C}$ [34]. KPS $(0.0070 \mathrm{~g}, 0.025$ $\mathrm{mmol}$ ) in $1.0 \mathrm{~mL}$ of $\mathrm{H}_{2} \mathrm{O}$ was added to the solution to initiate polymerization. The reaction was maintained at $75^{\circ} \mathrm{C}$ under nitrogen for 3 hours. The reaction was

\section{Experimental}

\subsection{Materials and reagents}

Cibacron Blue F3G-A dye (CB), $N$-isopropylacrylamide (NIPAm), N-N'-methylenebis(acrylamide) (BIS), allylamine (AA) and potassium persulfate (KPS) were purchased from Sigma-Aldrich, Inc, USA. Recombinant hGH $22 \mathrm{kDa}$ Humatrope was purchased from Lilly, International Standard for hGH (Cadaveric hGH), was purchased from NIBSC, UK, and synthetic urine (Surine, Negative Control for urine testing) was purchased from Dyna-Tek Industries. 18\% Tris-Glycine gel and Tris-Glycine SDS running buffer were purchased from Invitrogen Corporation, USA. GH Sample Diluent was purchased from Siemens Medical Solution Diagnostic. Urine for the experiments was collected from healthy donors with IRB approved protocol. subsequently allowed to cool to room temperature and stirred overnight. The reaction mixture was then transferred to $2 \mathrm{~mL}$ microcentrifuge tubes and the particles harvested and washed via centrifugation (Eppendorf 5415R centrifuge). After centrifuging the particle suspension for $20 \mathrm{~min}$ at $23^{\circ} \mathrm{C}$ and 16100 relative centrifugal force ( $\mathrm{rcf}$ ), the supernatant from each tube was decanted and the particles were redispersed in $1.0 \mathrm{~mL} \mathrm{H}_{2} \mathrm{O}$. This concentration/redispersion process was repeated for a total of five washes.

To obtain NIPAm/CB particles, CB (0.38 g, $0.45 \mathrm{mmol}$ ) was dissolved in $5 \mathrm{~mL}$ of $0.1 \mathrm{~mol} / \mathrm{L}$ aqueous sodium carbonate. The NIPAm/AA particle suspension ( $5 \mathrm{~mL}$ volume) was purged with nitrogen for 15 min with a medium stirring rate in a $100 \mathrm{~mL}$ three-neck round-bottom flask, after which solid sodium carbonate $(0.053 \mathrm{~g}, 0.50 \mathrm{mmol})$ was added to the suspension. The suspension was then stirred at room temperature under nitrogen for about $1 \mathrm{~min}$. The CB solution was then added to the NIPAm/ AA particle suspension, and the combined reaction

\section{圈国 Springer}


mixture was then stirred at room temperature under nitrogen for $48 \mathrm{~h}$. The resulting NIPAm/CB particles were harvested and washed using centrifugation as described earlier in the preparation of NIPAm/ AA particles. Dye loading was determined via spectrophotometry (Thermo Spectronic 20+). A calibration curve was constructed using $\mathrm{CB}$ stock solutions of known concentrations. The supernatants from the entire concentration/redispersion process were combined, and their absorbance at a wavelength of $608 \mathrm{~nm}$ was determined. The CB concentration of the combined supernatants was estimated using the calibration curve.

The synthesis of NIPAm/acrylic acid (AAc) particles has been described previously [16].

NIPAm/beta-cyclodextrin $(\beta-C D)$ particles were obtained as follows: NIPAm/N-(hydroxymethylacry lamide) (HMA) particles were first prepared: NIPAm $(0.92 \mathrm{~g})$ and BIS $(0.03 \mathrm{~g})$ were dissolved in $30 \mathrm{~mL}$ of $\mathrm{H}_{2} \mathrm{O}$ and then filtered with a $0.2 \mu \mathrm{m}$ filter nylon membrane. HMA (0.008 g) was added to the reaction flask, and the solution was purged with nitrogen for $30 \mathrm{~min}$. The solution was then heated to $70{ }^{\circ} \mathrm{C}$ and maintained at this temperature for $30 \mathrm{~min}$. KPS $(0.007 \mathrm{~g})$ in $1 \mathrm{~mL} \mathrm{H}_{2} \mathrm{O}$ was then added to the reaction flask to initiate polymerization. The reaction was maintained at $70{ }^{\circ} \mathrm{C}$ for $3 \mathrm{~h}$. The reaction was then removed from the heat and allowed to cool to room temperature overnight, with the resulting NIPAm/ HMA particles being harvested and washed using centrifugation as described earlier in the preparation of NIPAm/AA particles. Beta-cyclodextrin (0.12 g) was dissolved in $1 \% \mathrm{HCl}$ solution, and $5 \mathrm{~mL}$ of the NIPAm/HMA particle suspension was introduced into the reaction flask. The resulting suspension was then purged with nitrogen for $15 \mathrm{~min}$ at room temperature. After $15 \mathrm{~min}$, the suspension was heated to $80{ }^{\circ} \mathrm{C}$ and maintained at that temperature for $1 \mathrm{~h}$ under nitrogen with a medium stirring rate. The resulting NIPAm $/ \beta-C D$ particles were then harvested and washed using centrifugation as described earlier in the preparation of NIPAm/AA particles. Particle concentration was assessed by weighing the lyophilized particles obtained from a known volume of the particle suspension.

The dependence of particle size on temperature was determined via photon correlation spectroscopy (submicron particle size analyzer, Beckman Coulter). The measurement of particle diameter was performed using water as diluent (refractive index $(\mathrm{RI})=$ 1.333, diluent viscosity $=0.890 \mathrm{cP}$ ). The test angle was $90^{\circ}$. Average values were calculated for three measurements using a $200 \mathrm{~s}$ integration time, and the solutions were allowed to thermally equilibrate for $10 \mathrm{~min}$ before each set of measurements. Measured values were then converted to particle sizes via the Stokes-Einstein relationship [35]. Atomic force microscopy (AFM) images were acquired on particles using an NSCRIPTOR ${ }^{\mathrm{TM}}$ DPN® System (NanoInk). Particle suspensions ( $1 \mathrm{mg} / \mathrm{mL}$ ) were deposited on freshly cleaved mica under a humidified atmosphere for $15 \mathrm{~min}$ and dried under nitrogen before measurement. Images were acquired under AC mode using a silicon tip with a typical resonance frequency of $300 \mathrm{kHz}$ and a radius smaller than $10 \mathrm{~nm}$.

\subsection{Particle incubation with analyte solutions}

Aliquots of particles were incubated with $1 \mathrm{~mL}$ of buffers, Surine or human urine for $1 \mathrm{~h}$ at room temperature under slow rotation. After incubation, the particles were centrifuged $\left(7 \mathrm{~min}, 25^{\circ} \mathrm{C}, 16100\right.$ rcf), the supernatant was saved and the particles were washed three times by resuspending the pellets in $1 \mathrm{~mL}$ of water and centrifuging $\left(7 \mathrm{~min}, 25^{\circ} \mathrm{C}\right.$, $16100 \mathrm{rcf})$. The particles were then directly loaded on the gel or incubated with elution buffers. Incubations with $10 \mathrm{~mL}$ of Surine were performed with 50 $\mathrm{mL}$ centrifuge tubes (Nalgene) and particles were separated from urine by centrifugation $\left(45 \mathrm{~min}, 25^{\circ} \mathrm{C}\right.$, 18000 revolutions per minute (rpm)) and washed as previously described.

\subsection{Elution of hGH from particles}

The washed pellet of particles was incubated for 15 min at room temperature or for one hour at $38^{\circ} \mathrm{C}$ with proper amounts of elution. buffers. After incubation, the particles were centrifuged $\left(7 \mathrm{~min}, 25^{\circ} \mathrm{C}, 16100\right.$ rcf) and the eluate was saved. The elution step was repeated twice and the eluates were pooled together.

\subsection{SDS-PAGE and silver staining}

Sodium dodecyl sulfate polyacrylamide gel 


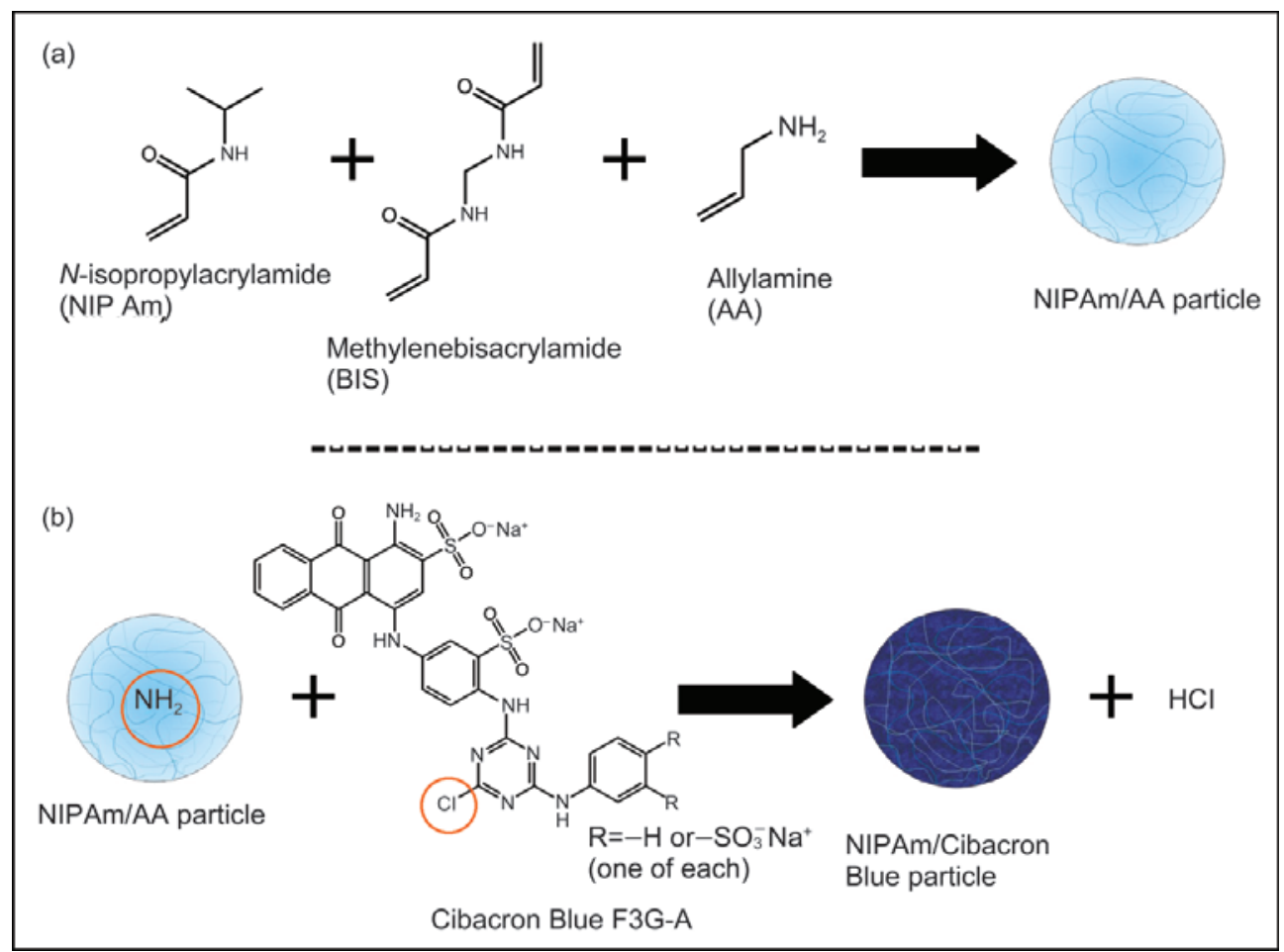

Figure 2 Chemical reactions for the synthesis of particles: (a) allylamine functionalized particles are created; (b) Cibacron Blue F3G-A dye is covalently incorporated into the particles via the amino group

electrophoresis (SDS-PAGE) was performed using $18 \%$ Tris-Glycine gel in the presence of Tris-Glycine SDS running Buffer on a Novex X-Cell IITM MiniCell (Invitrogen Corporation, USA), at $200 \mathrm{~V}$. The gels were stained by silver staining.

\subsection{Immunometric assay}

The concentration of hGH eluted from particles was measured using the Immulite 1000 Growth Hormone System (Siemens Medical Solution Diagnostic). Eluates were diluted in GH Sample Diluent, and assayed according to the manufacturer's instructions.

\section{Results and discussion}

\subsection{Synthesis and characterization of hydrogel NIPAm/}

\section{Cibacron Blue F3GA particles}

The hydrogel particles utilized in this study were obtained by incorporating Cibacron Blue F3G-A dye in $\mathrm{N}$-isopropylacrylamide (NIPAm)/allylamine (AA) particles. NIPAm/AA particles were synthesized via precipitation polymerization under a nitrogen atmosphere using BIS as cross linker. AA was added by copolymerization to the NIPAm particles in order to have an amino group that can bind to the triazine ring of the dye via $\mathrm{HCl}$ elimination (Fig. 2). The estimated dye loading was respectively $50 \%$ and $56 \%$ for the $5 \%$ and the $10 \%$ AA particles.

As shown in the AFM images (Fig. 3(a)) the particles are homogenous in size with a diameter of about $800 \mathrm{~nm}$. A picture of $2 \mathrm{~mL}$ vials of NIPAm/CB and NIPAm/AA particles is shown in Fig. 3(b). Light scattering analysis was conducted in the

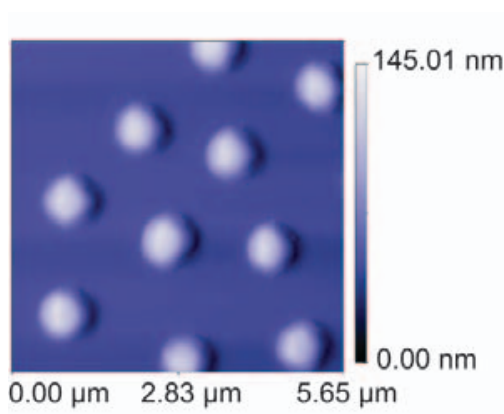

(a)

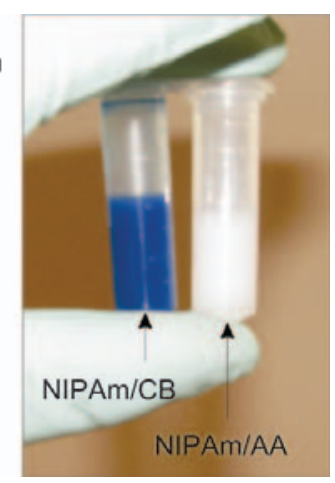

(b)
Figure 3 Characterization of Cibacron Blue F3G-A loaded particles: (a) atomic force microscopy (AFM) image showing size homogeneity; (b) picture of $2 \mathrm{~mL}$ vials of NIPAm/CB and NIPAm/AA particles 
temperature range 20 to $50^{\circ} \mathrm{C}$; as reported in Fig. 4(a) the diameter of particles showed an inverse relation with temperature, decreasing from the maximum average value of $884.9 \mathrm{~nm} \pm 8.5 \mathrm{~nm}$ at $20{ }^{\circ} \mathrm{C}$ to a minimum of $255.9 \mathrm{~nm} \pm 5.4 \mathrm{~nm}$ measured at $50{ }^{\circ} \mathrm{C}$, consistent with the typical temperature dependent behavior of hydrogel nanoparticles. Histograms based on intensities of particle size distribution for each temperature run are reported in Fig. 4(b).

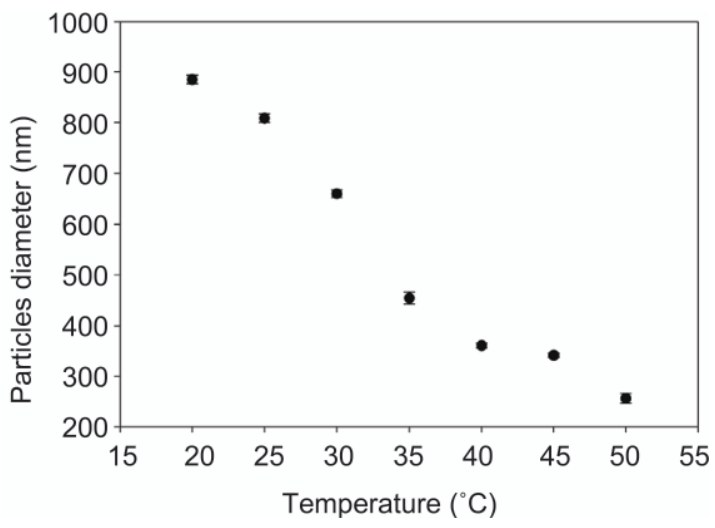

(a)

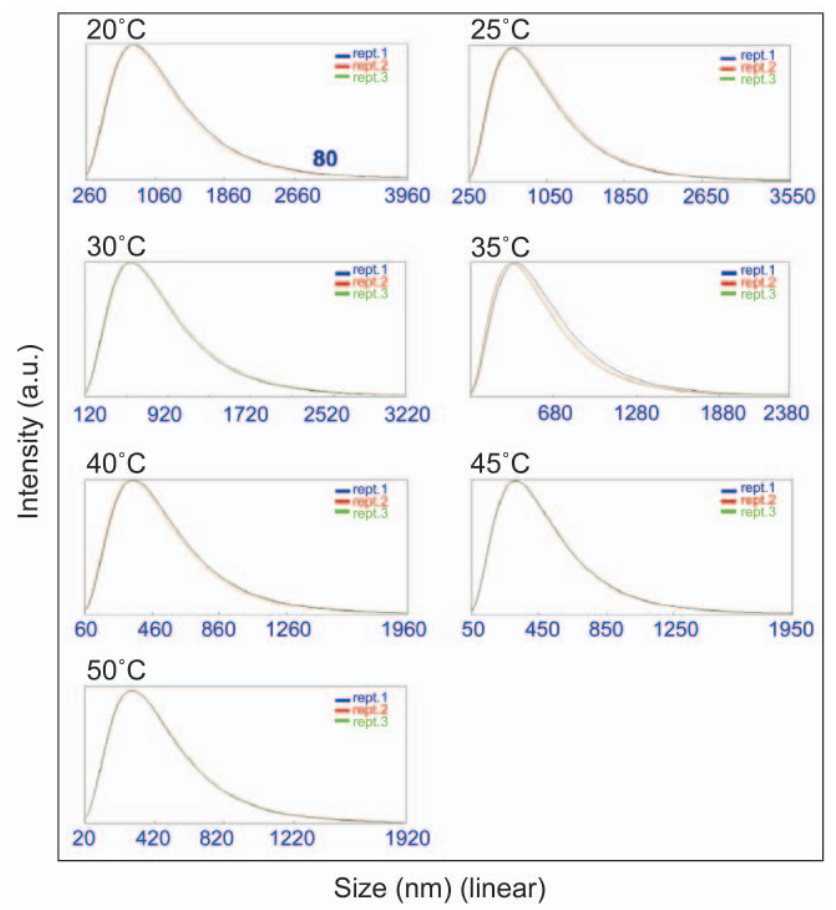

(b)

Figure 4 Photon correlation spectroscopy analysis of dependence of particle size on temperature: (a) plot of average values of light scattering measurements of particle diameter at different temperatures. Hydrogel particles are thermoresponsive; (b) histograms showing the amplitude of the particle size distribution at each temperature
The concentration of particles was assessed by weighing the lyophilized particles $(5.7 \mu \mathrm{g} / \mu \mathrm{L})$.

Hydrogels are jelly-like materials composed of a network of polymeric chains in which the degree of porosity can be tuned by changing the percentage of the cross-linker $N$ - $N^{\prime}$-methylenebis(acrylamide) (BIS). This polymeric network acts as a sieve, allowing NIPAm/CB particles to perform size exclusion chromatography in solution. The degree of homogeneity in the distribution of pore sizes in the particles can be assessed by the sharpness of the molecular weight cut-off. In order to evaluate the size sieving properties of NIPAm/CB particles and define the molecular weight cut-off we used a mixed solution of proteins of known molecular weight. Aprotinin (MW $6.5 \mathrm{kDa}$, Sigma-Aldrich), lysozyme (MW $14.4 \mathrm{kDa}$, Sigma-Aldrich), bovine serum albumin, BSA (MW 66 kDa, Fisher Scientific), ovalbumin (MW $45 \mathrm{kDa}$, Sigma-Aldrich), hGH (MW $22 \mathrm{kDa}$, Humatrope Lilly), and insulin growth factor binding protein 7, IGFBP7 (MW $31 \mathrm{KDa}$, Preprotech) were dissolved in Surine at $\mathrm{pH} 5$ at a concentration of $0.1 \mu \mathrm{g} / \mu \mathrm{L}$, and incubated with $100 \mu \mathrm{L}(570 \mu \mathrm{g})$ of NIPAm/CB particles for $30 \mathrm{~min}$ at room temperature. The suspension was then centrifuged and the particles washed with water. Particles and supernatant were analyzed by SDS-

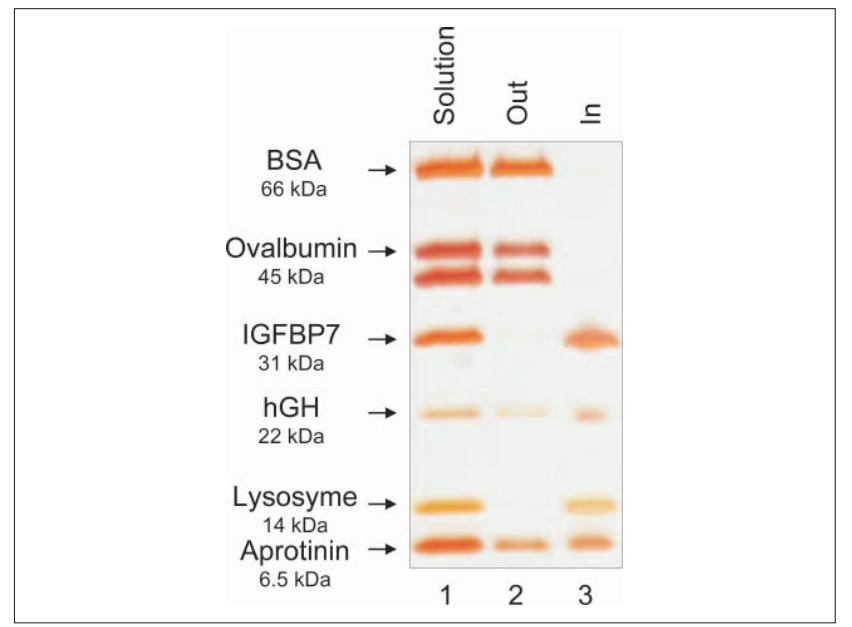

Figure 5 Evaluation of size exclusion properties of NIPAm/CB particles by SDS-PAGE. Particles were incubated with a mixture of proteins with a molecular weight range between 66 and $6.5 \mathrm{kDa}$, dissolved in Surine. Lane 1 protein mixture; Lane 2 supernatant (Out), Lane 3 particle content (In). Only proteins with a molecular weight lower than $45 \mathrm{KDa}$ were trapped by the particles; ovalbumin and BSA were completely excluded 
PAGE (Fig. 5). We observed that only proteins with molecular weight less than $45 \mathrm{kDa}$ were captured by the particles (Lane 3) and the molecular weight cut-off was estimated between 45 and $31 \mathrm{kDa}$. The sharpness of the molecular weight cut-off suggests that the distribution of pore size in the particles was very homogeneous.

\subsection{Harvesting of hGH by NIPAm/Cibacron Blue F3GA particles}

In order to select the best performing particles to harvest hGH from solution, we compared four classes of hydrogel NIPAm nanoparticles containing different baits (CB ( $5 \%$ and $10 \%$ AA), AA, AAc and $\beta-C D)$. Recombinant hGH was dissolved at a concentration of $0.2 \mathrm{mg} / \mathrm{mL}$ in sodium citrate

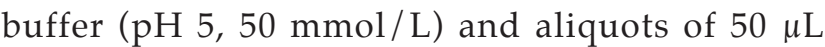
were incubated with $50 \mu \mathrm{L}$ of each different class of particles for $1 \mathrm{~h}$ at room temperature. After incubation, the supernatant was saved and the particles were washed. Supernatants and particles were subjected to SDS PAGE analysis and silver stained (Fig. 6). NIPAm/CB particles proved to be the

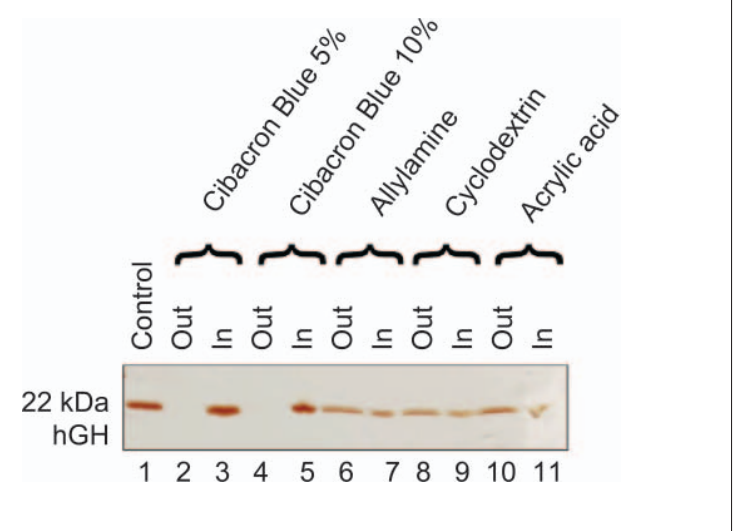

Figure 6 SDS-PAGE analysis of particles carrying different baits and their ability to harvest hGH. Lane $1 \mathrm{hGH}$ control; Lane 2 Cibacron Blue 5\% loaded particle supernatant (Out); Lane 3 Cibacron Blue $5 \%$ loaded particle content (In); Lane 4 Cibacron Blue 10\% loaded particle supernatant (Out); Lane 5 Cibacron Blue 10\% loaded particle content (In); Lane 6 allylamine particle supernatant (Out); Lane 7 allylamine particle content (In); Lane 8 beta-cyclodextrin loaded particle supernatant (Out); Lane 9 beta-cyclodextrin loaded particle content (In); Lane 10 acrylic acid particle supernatant (Out); Lane 11 acrylic acid particle content (In). Cibacron Blue 5\% and 10\% had the best affinity for hGH of all the particles tested and both completely depleted the supernatant and achieved a high degree of concentration of the hGH most efficient in harvesting hGH from solution (Lanes $3,5)$, leaving undetectable concentrations of the hormone in the bulk supernatant, as demonstrated by the corresponding blank lanes on the gel (Lanes 2, 4). Only a small amount of hormone was sequestered by $\beta-C D$, NIPAm/AA, and NIPAm/AAc bait particles (Lanes 6-11), indicative of a weak affinity of the baits for the analyte. The NIPAm/AAc particles carry a negative charge at $\mathrm{pH}$ greater than 3.5 that leads to stronger electrostatic interactions with cationic species, whereas the human hGH (pI 5.27) under the experimental conditions described is expected to be almost neutral. Moreover at the physiological $\mathrm{pH}$ of urine ( $\mathrm{pH} 4-10)$, the protein is expected to be mostly negatively charged, thus explaining why the NIPAm/AAc particles were not effective for hGH harvesting. The NIPAm/AA particles are positively charged but their efficiency in capturing the hormone is not as high as that of the NIPAm/CB particles, because the specific interaction with the target is conferred primarily by the bait. It has been widely shown in the literature that $\beta-C D$ has high affinities for small molecules such as cholesterol, steroids, and DOPA [36-38], and it therefore acts as a good negative control for hGH uptake.

\subsection{Harvesting and concentration of hGH by NIPAm/CB particles in urine models}

Human urine contains a multitude of organic and inorganic compounds, and is characterized by high levels of salt concentration and $\mathrm{pH}$ between 4 and 10. Urea is the most abundant nitrogenous metabolic waste (comprising about $95 \%$ of the nitrogen content of urine). Salts and urea can potentially influence the behavior of a harvesting nanoparticle and interfere with the interactions between CB and hGH. In order to evaluate hGH harvesting performance in conditions as similar as possible to physiological urine, we studied the effects of urea, salts and different $\mathrm{pH}$ levels on the hGH harvesting efficiency of the particles.

Samples of hGH $(0.01 \mathrm{mg} / \mathrm{mL})$ were spiked in the following solutions: urea $(0.7 \mathrm{mg} / \mathrm{mL}$, physiological concentration), $\mathrm{KCl}(6.0 \mathrm{mg} / \mathrm{mL}$, comparable to the total amount of salts in urine) and different buffered solutions with $\mathrm{pH}$ values ranging from 4 to 10 (50

\section{国㬎: Springer}




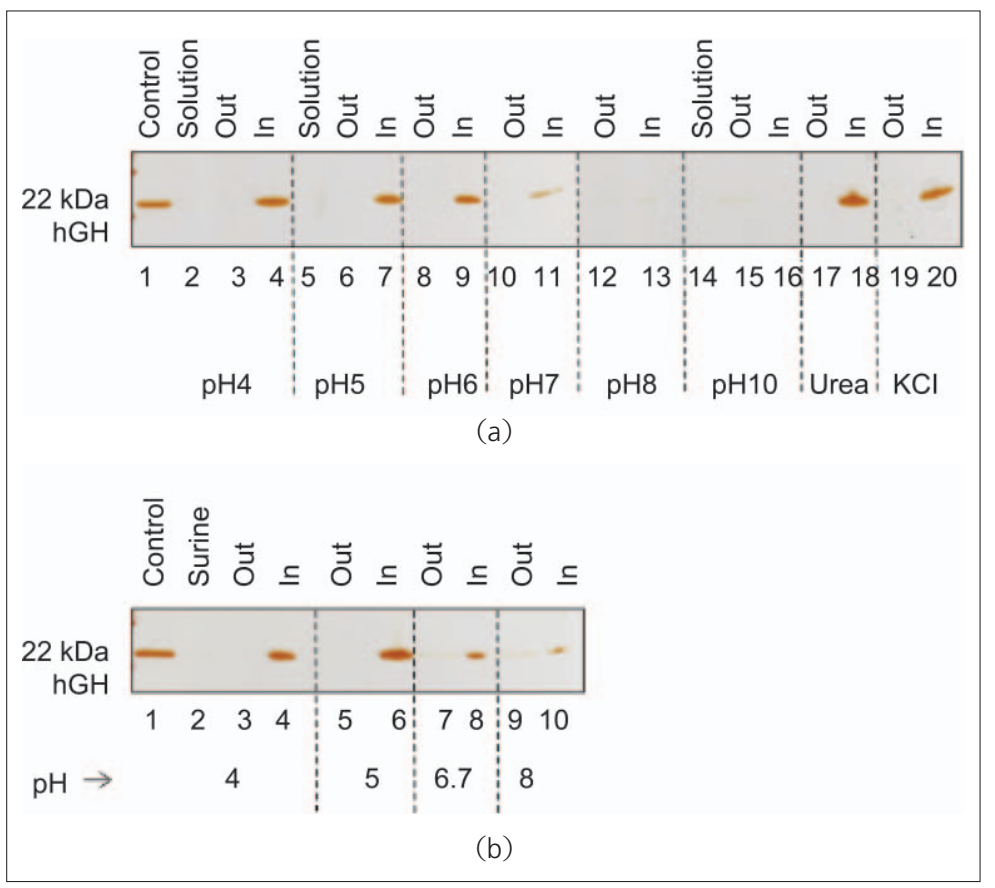

Figure 7 SDS PAGE analysis of particles incubated with solutions of different $\mathrm{pH}$ values, in the presence of urea and salts. (a) Study of the effect of $\mathrm{pH}$, urea and $\mathrm{KCl}$ on particle uptake of hGH. Lane $1 \mathrm{hGH}$ control; Lane $20.01 \mathrm{mg} / \mathrm{mL} \mathrm{hGH}$ solution at $\mathrm{pH} 4$; Lane 3 NIPAm/CB particle supernatant at pH 4 (Out); Lane 4 NIPAm/CB particle content at $\mathrm{pH} 4$ (In); Lane $50.01 \mathrm{mg} / \mathrm{mL}$ hGH solution at $\mathrm{pH}$ 5; Lane $6 \mathrm{NIPAm} / \mathrm{CB}$ particle supernatant at pH 5 (Out); Lane 7 NIPAm/CB particle content at pH 5 (In); Lane 8 NIPAm/CB particle supernatant at pH 6 (Out); Lane 9 NIPAm/CB particle content at pH 6 (In); Lane $10 \mathrm{NIPAm} / \mathrm{CB}$ particle supernatant at pH 7 (Out); Lane 11 NIPAm/CB particle content at pH 7 (In); Lane 12 NIPAm/CB particle supernatant at $\mathrm{pH} 8$ (Out); Lane $13 \mathrm{NIPAm} / \mathrm{CB}$ particle content at pH 8 (In); Lane $140.01 \mathrm{mg} / \mathrm{mL} \mathrm{hGH}$ solution at $\mathrm{pH}$ 10; Lane $15 \mathrm{NIPAm} / \mathrm{CB}$ particle supernatant at pH 10 (Out); Lane 16 NIPAm/CB particle content at pH 10 (In); Lane 17 NIPAm/CB particle supernatant in presence of urea (Out); Lane 18 NIPAm/CB particle content in presence of urea (In); Lane 19 NIPAm/CB particle supernatant in presence of $\mathrm{KCl}$ (Out); Lane $20 \mathrm{NIPAm} / \mathrm{CB}$ particle content in presence of $\mathrm{KCl}$ (In). Uptake of hGH is higher at lower $\mathrm{pH}$ and it is not hindered by the presence of urea or $\mathrm{KCl}$. (b) SDS PAGE analysis of NIPAm/CB particles incubated with hGH diluted in synthetic urine (Surine) at different $\mathrm{pH}$ values. Lane $1 \mathrm{hGH}$ control; Lane $20.01 \mathrm{mg} / \mathrm{mL}$ hGH solution in Surine; Lane $3 \mathrm{NIPAm} / \mathrm{CB}$ particle supernatant at $\mathrm{pH} 4$ (Out); Lane 4 NIPAm/CB particle content at pH 4 (In); Lane 5 NIPAm/CB particle supernatant at pH 5 (Out); Lane 6 NIPAm/CB particle content at pH 5 (In); Lane 7 NIPAm/CB particle supernatant at pH 6.7 (Out); Lane 8 NIPAm/CB particle content at pH 6.7 (In); Lane 9 NIPAm/CB particle supernatant at pH 8 (Out); Lane $10 \mathrm{NIPAm} / \mathrm{CB}$ particle content at $\mathrm{pH} 8$ (In). Particles successfully sequestered hGH from solution, and the efficiency was higher at lower $\mathrm{pH}$ and supernatants were analyzed by SDSPAGE analysis. As shown in Fig. 7(a), physiological concentrations of urea and salts did not hinder the ability of particles to capture hGH (Lanes 17-20). The harvesting was optimal in the $\mathrm{pH}$ range from 4 to 6 (Lanes 3-9). Under these conditions, particles were capable of increasing hGH concentration from an undetectable level (Lane 2) to a clearly visible band (Lanes $4,7,9)$. Increasing the solution $\mathrm{pH}$ caused a decrease in harvesting efficiency. These data suggest that acidic conditions favor the molecular interaction between the dye and the hGH.

We confirmed our results by spiking hGH in Surine which is a medium routinely used as a negative control for urine tests. Aliquots of hGH $(0.01 \mathrm{mg} / \mathrm{mL})$ were dissolved in Surine at $\mathrm{pH}$ values of 4, 5, 6.7, and 8. The $\mathrm{pH}$ of Surine was 6.7 at $22^{\circ} \mathrm{C}$, and therefore the $\mathrm{pH}$ was adjusted as necessary by adding appropriate amounts of $\mathrm{HCl}$ or $\mathrm{NaOH}$. Aliquots of $100 \mu \mathrm{L}(570 \mu \mathrm{g})$ of particles were incubated with $1 \mathrm{~mL}$ of Surine. Harvesting of hGH was evaluated by SDS PAGE analysis. Sequestration extent and concentrations of hGH were estimated for each $\mathrm{pH}$ value (Fig. 7(b)); pH 5 was assessed as the optimal uptake condition (Lanes 5, 6).

Taken together, these results suggested that acidic conditions were more favorable for hGH uptake than basic conditions, and therefore we decided to carry out the incubations at $\mathrm{pH} 5$, which is representative of physiological conditions, and then to increase the $\mathrm{pH}$ as a means of eluting $\mathrm{hGH}$ from the particles. $\mathrm{mmol} / \mathrm{L}$ sodium citrate buffer titrated to $\mathrm{pH} 4,5$ and 6; $50 \mathrm{mmol} / \mathrm{L}$ Tris $\mathrm{HCl}$ buffer titrated to $\mathrm{pH} 7$ and 8; $50 \mathrm{mmol} / \mathrm{L}$ carbonate-bicarbonate buffer titrated to $\mathrm{pH}$ 10). One milliliter of each solution was incubated with $100 \mu \mathrm{L}(570 \mu \mathrm{g})$ of NIPAm/CB particles. Particles were centrifuged and washed and particles

\subsection{Time course studies}

In order to understand the kinetics of hGH sequestration by $\mathrm{CB}$ particles, an uptake time course study was performed. Aliquots of $1 \mathrm{~mL}$ of 0.01 $\mathrm{mg} / \mathrm{mL}$ hGH in Surine at $\mathrm{pH} 5$ were incubated with 
$100 \mu \mathrm{L}(570 \mu \mathrm{g})$ of $\mathrm{CB}$ particles and the incubation was allowed to proceed for 1, 5, 20, 40, and $60 \mathrm{~min}$. Particles were separated by centrifugation and washed. Particles and supernatants were subjected to SDS PAGE analysis (Fig. 8(a)). Capture of hGH was a very fast process; after only one minute the majority of hGH was detectable inside the particles (Lane 3). Moreover, in order to test the capability of the nanoparticles to preserve captured hGH from

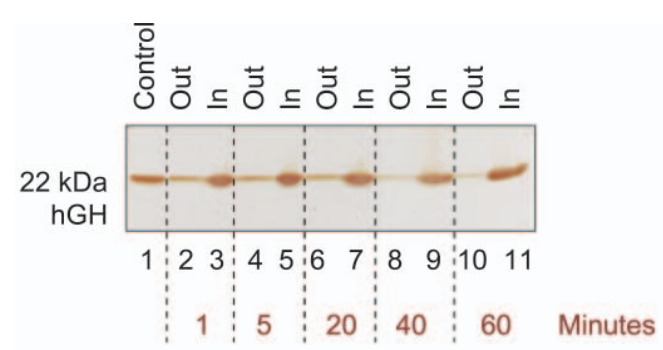

(a)

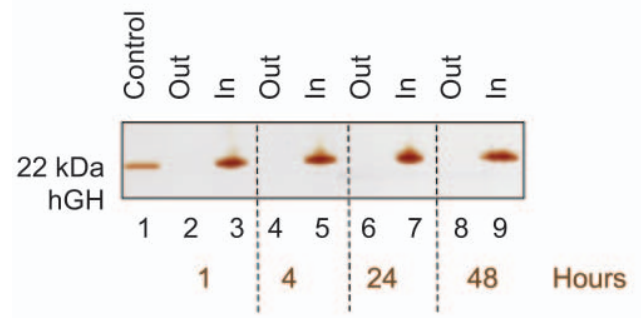

(b)

Figure 8 SDS PAGE analysis of time studies. (a) Uptake time course. Lane 1 hGH control; Lane 2 NIPAm/CB particle supernatant after 1 min incubation (Out); Lane 3 NIPAm/CB particle content after 1 min incubation (In); Lane 4 NIPAm/CB particle supernatant after 5 min incubation (Out); Lane 5 NIPAm/CB particle content after 5 min incubation (In); Lane 6 NIPAm/CB particle supernatant after 20 min incubation (Out); Lane 7 NIPAm/CB particle content after $20 \mathrm{~min}$ incubation (In); Lane 8 NIPAm/CB particle supernatant after $40 \mathrm{~min}$ incubation (Out); Lane 9 NIPAm/CB particle content after $40 \mathrm{~min}$ incubation (In); Lane 10 NIPAm/CB particle supernatant after $60 \mathrm{~min}$ incubation (Out); Lane 11 NIPAm/CB particle content after 60 min incubation (In). The sequestration process was very fast, with the majority of hGH being captured by particles after one minute. (b) Preservation time course. Lane $1 \mathrm{hGH}$ control; Lane 2 NIPAm/CB particle supernatant after $1 \mathrm{~h}$ (Out); Lane 3 NIPAm/CB particle content after $1 \mathrm{~h}$ incubation (In); Lane 4 NIPAm/CB particle supernatant after $4 \mathrm{~h}$ incubation (Out); Lane 5 NIPAm/CB particle content after $4 \mathrm{~h}$ incubation (In); Lane 6 NIPAm/CB particle supernatant after $24 \mathrm{~h}$ incubation (Out); Lane 7 NIPAm/CB particle content after 24 h incubation (In); Lane 8 NIPAm/CB particle supernatant after 48 h incubation (Out); Lane 9 NIPAm/CB particle content after $48 \mathrm{~h}$ incubation (In). Once captured by particles, hGH remains stable up to at least $48 \mathrm{~h}$ degradation over time, we performed a time course experiment to assess the stability of the sequestered hGH over a period of $48 \mathrm{~h}$. CB particles $(100 \mu \mathrm{L}, 570 \mu \mathrm{g})$ were incubated with $1 \mathrm{~mL}$ of $0.01 \mathrm{mg} / \mathrm{mL}$ hGH in Surine for 1, 4, 24, and $48 \mathrm{~h}$ at room temperature, as described above. SDS PAGE analysis showed no detectable loss of hGH harvesting, and full hGH preservation at each incubation time (Fig. 8(b)).

\subsection{Sequestration by CB particles of the different isoforms of cadaveric hGH spiked in Surine}

Since endogenous, naturally produced hGH exists as a series of different size isoforms, but recombinant $\mathrm{hGH}$ consists of only the $22 \mathrm{kDa}$ form, it was necessary to assess whether $\mathrm{CB}$ particles sequestered all three main isoforms of hGH $(22,20$, and $17 \mathrm{kDa})$. The cadaveric WHO international standard for hGH (which contains all the natural isoforms) was spiked in Surine at a concentration of $0.01 \mathrm{mg} / \mathrm{mL}$ and incubated with $100 \mu \mathrm{L}(570 \mu \mathrm{g})$ of $\mathrm{CB}$ particles. Particles were separated from Surine and washed as previously described. Particles and supernatant were subjected to SDS-PAGE analysis (Fig. 9). As shown in Lane 3, particles sequestered and concentrated all three isoforms $(22,20$, and $17 \mathrm{kDa})$ so that the less abundant forms became detectable by SDS-PAGE. The starting solution prior to particle sequestration was loaded in Lane 1 and the only visible band corresponds to the $22 \mathrm{kDa}$ form.

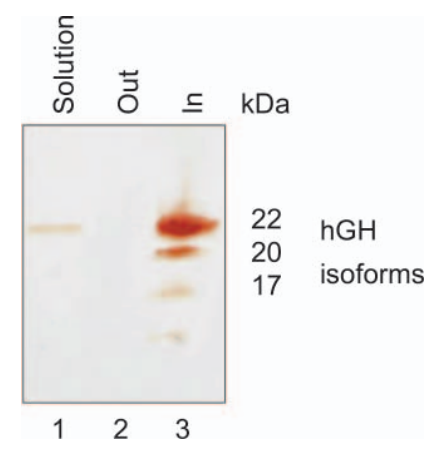

Figure 9 SDS PAGE analysis of cadaveric hGH spiked in Surine and incubated with particles. Lane $10.01 \mathrm{mg} / \mathrm{mL}$ cadaveric hGH solution in Surine; Lane 2 NIPAm/CB particle supernatant (Out); Lane 3 NIPAm/ CB particle content (In). Particles sequestered all the three major isoforms of $\mathrm{hGH}(22,20$, and $17 \mathrm{kDa})$ and increased the concentration of the minor isoforms, so that they could be detected by silver staining 


\subsection{Harvesting and concentration of IL-8 by NIPAm/CB particles in Surine}

$\mathrm{CB}$ dye is an affinity ligand for a vast class of proteins: in fact it is well known for its affinity for nucleotide binding proteins [30], and various mechanisms of interaction between CB dye and proteins have been hypothesized, such as electrostatic, hydrophobic, hydrogen bonding and charge transfer interactions [29]. Therefore, NIPAm/CB particles can capture and concentrate a wide class of low molecular weight proteins in solution. The ability of NIPAm/CB nanoparticles to capture and concentrate interleukin 8 (IL-8), another potential biomarker of disease, was tested in Surine. IL -8 is a member of the class of CXC chemokines and acts as a proinflammatory and proangiogenic cytokine associated with tumor progression, prognosis and survival in several types of cancer [39-41]. Recently, serum and urine levels in non-Hodgkin's lymphoma (NHL) patients have been investigated and IL-8 levels were found to be significantly higher in patients with NHL than in healthy individuals [33].

IL-8 (8.4 kDa, AbD Serotec) was spiked in $1 \mathrm{~mL}$ of Surine at a concentration of $0.004 \mathrm{mg} / \mathrm{mL}$ and the solution was incubated with $100 \mu \mathrm{L}$ (570 $\mu \mathrm{g}$ ) of NIPAm/ CB particles. Particles were centrifuged and washed as previously described. Particles and supernatant were then analyzed by SDS-PAGE and silver staining (Fig. 10). It was found that NIPAm/CB particles captured and concentrated IL-8 in solution (Lane 3) and completely removed IL-8 from the supernatant (Lane 2).

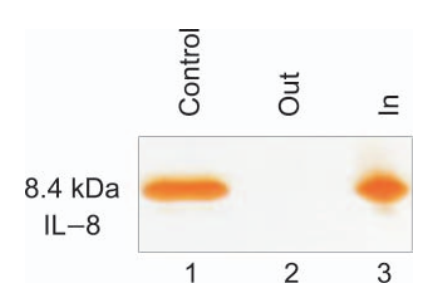

Figure 10 SDS-PAGE analysis of NIPAm/CB particles incubated with IL-8 diluted in Surine. Lane 1) IL-8 Control, Lane 2 NIPAm/CB particle supernatant (Out), Lane 3 NIPAm/CB particle content (In)

\subsection{Elution conditions}

In order to optimize the elution conditions, aliquots of $1 \mathrm{~mL}$ of $0.01 \mathrm{mg} / \mathrm{mL}$ hGH in Surine at $\mathrm{pH} 5$ were incubated with $100 \mu \mathrm{L}(570 \mu \mathrm{g})$ of CB particles and washed as previously described. The particle pellets were subsequently incubated for $15 \mathrm{~min}$ with the following elution buffers: $50 \mathrm{mmol} / \mathrm{L}$ Tris $\mathrm{HCl}$ $\mathrm{pH} 7$ and 8, and $50 \mathrm{mmol} / \mathrm{L}$ carbonate-bicarbonate $\mathrm{pH} 10$ and centrifuged $\left(7 \mathrm{~min}, 25^{\circ} \mathrm{C}, 16100 \mathrm{rcf}\right)$. We obtained partial elution at all $\mathrm{pH}$ values, with higher yields under more basic conditions (Fig. 11(a)).
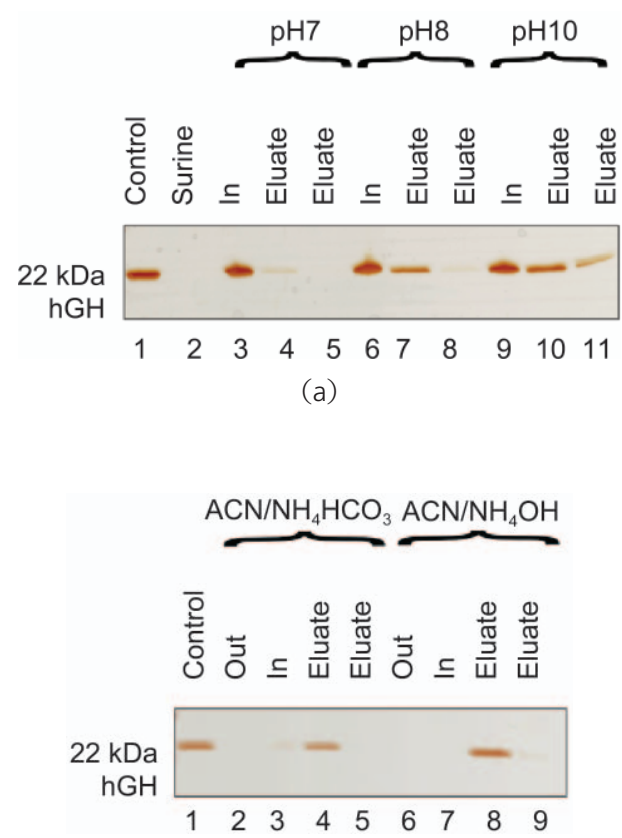

(b)

Figure 11 SDS PAGE analysis for optimizing the elution conditions. (a) Lane $1 \mathrm{hGH}$ control; Lane $20.01 \mathrm{mg} / \mathrm{mL}$ hGH solution in Surine; Lane 3 NIPAm/CB particle content after elution at pH 7 (In); Lane 4 NIPAm/CB particle content eluted at $\mathrm{pH} 7$ (Eluate); Lane $5 \mathrm{NIPAm} / \mathrm{CB}$ particle content eluted at $\mathrm{pH} 7$ (Eluate); Lane 6 NIPAm/CB particle content after elution at $\mathrm{pH} 8$ (In); Lane 7 NIPAm/CB particle content eluted at $\mathrm{pH} 8$ (Eluate); Lane 8 NIPAm/CB particle content eluted at $\mathrm{pH} 8$ (Eluate); Lane 9 NIPAm/CB particle content after elution at $\mathrm{pH} 10$ (In); Lane $10 \mathrm{NIPAm} / \mathrm{CB}$ particle content eluted at $\mathrm{pH} 10$ (Eluate); Lane $11 \mathrm{NIPAm} / \mathrm{CB}$ particle content eluted at pH 10 (Eluate). Partial elution of hGH from particles was obtained with buffers at $\mathrm{pH} 7,8$, and 10. (b) Lane 1 hGH control; Lane 2 NIPAm/CB particle supernatant (Out); Lane 3 NIPAm/CB particle content after elution with acetonitrile/ $\mathrm{NH}_{4} \mathrm{HCO}_{3}(\mathrm{In})$; Lane 4 NIPAm/CB particle content eluted with acetonitrile/ $\mathrm{NH}_{4} \mathrm{HCO}_{3}$ (Eluate); Lane $5 \mathrm{NIPAm} / \mathrm{CB}$ particle content eluted with acetonitrile/ $\mathrm{NH}_{4} \mathrm{HCO}_{3}$ (Eluate); Lane $6 \mathrm{NIPAm} /$ CB particle supernatant (Out); Lane 7 NIPAm/CB particle content after elution with acetonitrile/ $\mathrm{NH}_{4} \mathrm{OH}$ (In); Lane 8 NIPAm/CB particle content eluted with acetonitrile/ $\mathrm{NH}_{4} \mathrm{OH}$ (Eluate); Lane 9 NIPAm/CB particle content eluted with acetonitrile/ $\mathrm{NH}_{4} \mathrm{OH}$ (Eluate). Complete elution of hGH from particles was obtained with acetonitrile/ $\mathrm{NH}_{4} \mathrm{OH}$ 
Since our aim was complete retrieval of hGH from dye particles, we tested stronger elution buffers $\left(50 \%\right.$ acetonitrile $(\mathrm{ACN}) / 50 \mathrm{mmol} / \mathrm{L} \mathrm{NH}_{4} \mathrm{HCO}_{3}$ and $\left.60 \% \mathrm{ACN} / 4 \% \mathrm{NH}_{4} \mathrm{OH}\right)$. Based on the temperature dependence of particle size, we performed the elution for one hour at $38^{\circ} \mathrm{C}$ in order to diminish the volume of the particles and facilitate the elution of proteins (Fig. 11(b)). Complete elution was obtained by using $60 \% \mathrm{ACN} / 4 \% \mathrm{NH}_{4} \mathrm{OH}$ buffer (Lanes 7, 8, and 9) while nearly complete elution was obtained with $50 \%$ $\mathrm{ACN} / 50 \mathrm{mmol} / \mathrm{L} \mathrm{NH}_{4} \mathrm{HCO}_{3}$ (Lanes 3, 4, and 5).

\subsection{Amplification of hGH concentration as measured by Immulite 1000 growth hormone system}

The above data demonstrate that the NIPAm/CB nanoparticles were efficiently and rapidly able to capture and concentrate hGH dissolved at known concentrations in synthetic urine. In order to evaluate the concentration factor obtained using the particles as a trap, we used an immunometric assay, Immulite 1000 Growth Hormone System. Immulite 1000 is a solid phase chemiluminescent immunometric assay platform, routinely used for the quantitative measurement of hGH in serum, whose linear range extends from 0.05 to $40 \mathrm{ng} / \mathrm{mL}$. The estimated hGH concentration in a healthy individual's urine is in the range of low $\mathrm{pg} / \mathrm{mL}$, which is lower than the detection limit of Immulite. Therefore, we tested the ability of nanoparticles to concentrate hGH from undetectable levels in model solutions. The goal was to raise the concentration of hGH into the linear range for detection by the Immulite assay.

Surine is a model for urine that does not contain any protein. In order to better mimic real conditions, proteins were added to Surine at concentrations in the physiological range. As previously discussed, CB has affinity for a large class of proteins that, present in urine, could compete with hGH for the binding sites in the particles, reducing the efficiency of capture $[42,43]$. In order to test the binding capacity of NIPAm/CB particles, we spiked recombinant $\mathrm{hGH}$ in $1 \mathrm{~mL}$ of Surine at $\mathrm{pH} 5$, alone or in the presence of the following proteins: aprotinin (MW $6.5 \mathrm{kDa}$ ), lysozyme (MW $14.4 \mathrm{kDa}$ ), BSA (MW $66 \mathrm{kDa})$, trypsin inhibitor $(21.5 \mathrm{kDa})$, and chemokine
(C-C motif) ligand 28, CCL28 (MW $14 \mathrm{kDa}$ ). Each protein was dissolved in Surine at a concentration of $200 \mathrm{ng} / \mathrm{mL}$, the total protein concentration was $1 \mu \mathrm{g} / \mathrm{mL}$, and the ratio of $\mathrm{hGH}$ to total protein in solution was 1:10000. These solutions were incubated with $100 \mu \mathrm{L}(570 \mu \mathrm{g})$ of NIPAm/CB particles. The incubation, washing and elution of particles was performed as previously described. Then, $30 \mu \mathrm{L}$ of Surine, supernatant and eluate were diluted 1:10 in GH Sample Diluent, and hGH concentration was measured by Immulite assay. As shown in Fig. 12 , hGH concentration in Surine in the absence of competitors was raised from $130 \mathrm{pg} / \mathrm{mL}$ to $2.93 \mathrm{ng} /$ $\mathrm{mL}$, and hGH was not detectable in the supernatant. In presence of competing proteins, a starting hGH concentration of $60 \mathrm{pg} / \mathrm{mL}$ was measured in Surine, while hGH concentration in the eluate was $2.85 \mathrm{ng} /$ $\mathrm{mL}$. This demonstrates that the presence of potential protein competitors does not affect the efficiency of the particles in capturing hGH in solution.

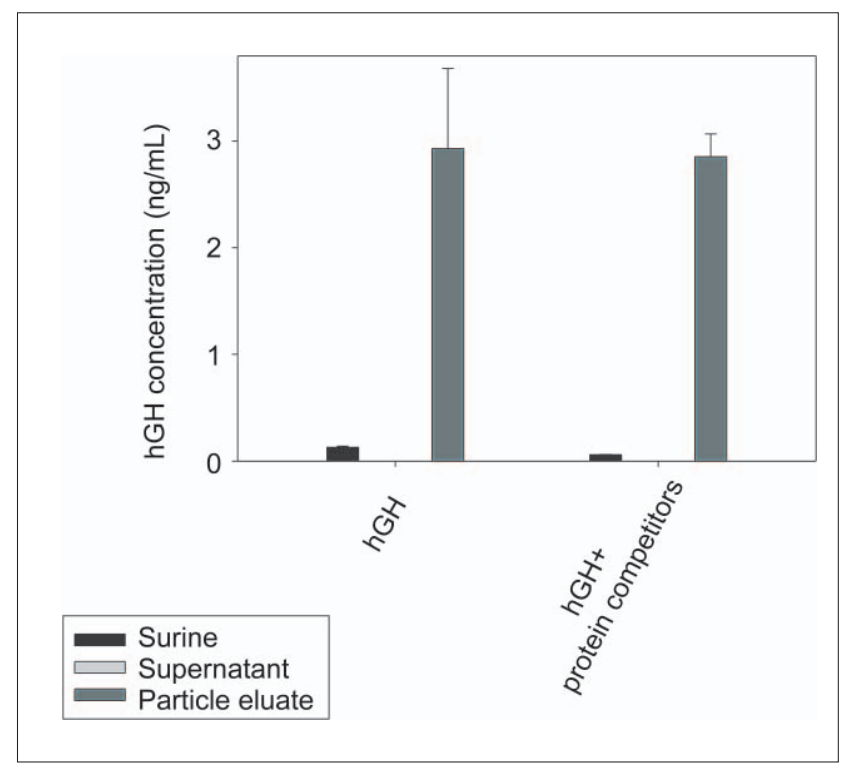

Figure 12 Immulite assay readings for NIPAm/CB particles incubated with two different urine models containing $\mathrm{hGH}$ and Surine with and without interfering proteins. The efficiency with which the particles concentrated hGH in Surine is not affected by the presence of proteins that may compete with the hormone for binding to the $C B$ bait

Using a dose-saturation study, we evaluated the amount of particles required to collect all the hGH present in solution for a standard urine collection volume. Aliquots of $1 \mathrm{~mL}$ of Surine containing 
$1 \mathrm{ng} / \mathrm{mL}$ of recombinant hGH were incubated with different aliquots of particles $(20,50,100$, $200,400 \mu \mathrm{L}$ ), corresponding to $114,285,570,1140$, and $2850 \mu \mathrm{g}$, respectively. Washing and elution of captured hGH analyte with $60 \% \mathrm{ACN} / 4 \% \mathrm{NH}_{4} \mathrm{OH}$ were performed as described above. Equal volumes $(30 \mu \mathrm{L})$ of Surine solution and of eluate from the particles were quantified by an Immulite 1000 hGH assay. Samples were diluted 1:10 in GH Sample Diluent. In Fig. 13(a), hGH concentration in the starting solution $(0.08 \mathrm{ng} / \mathrm{mL})$ is depicted by a horizontal line; the plateau was reached with an incubation of $570 \mu \mathrm{g}$ of particles. The same saturation study was performed with recombinant hGH spiked in human urine and cadaveric hGH spiked in human urine. The total protein concentration of human urine was $37.9 \mu \mathrm{g} / \mathrm{mL} \pm 6.67 \mu \mathrm{g} / \mathrm{mL}$, as measured by the Bradford Assay. The results are reported in Fig. 13(b) and Fig. 13(c), respectively. Notably, the particles were able to capture recombinant and cadaveric hGH spiked in human urine, showing that no interference was caused by the presence of proteins or any other physiological constituent of urine.

Further studies were performed to better understand the amplification power of the NIPAm/CB particles. Appropriate amounts of hGH were dissolved in separate samples of Surine to give concentrations of $<0.05 \mathrm{ng} / \mathrm{mL}$ and concentration of $0.3 \mu \mathrm{g} / \mathrm{mL}$. Aliquots of $1 \mathrm{~mL}$ of each solution were incubated with $100 \mu \mathrm{L}(570 \mu \mathrm{g})$ of particles. As shown in Fig. 14, when starting from an undetectable hGH concentration $(<0.05 \mathrm{ng} / \mathrm{mL})$, Immulite readings of hGH eluted from the particles gave a value of $2.0 \mathrm{ng} /$ $\mathrm{mL}$. When starting from a $0.3 \mathrm{ng} / \mathrm{mL}$ hGH solution, the concentration of hGH in the particle eluate was brought into the linear range of the Immulite assay.

In an attempt to mimic conditions more relevant to clinical settings, incubations of an initial volume of Surine of $10 \mathrm{~mL}$ were performed with $1 \mathrm{~mL}$ (5.7 mg) of particles. The volume ratio between the starting urine solution and the particle eluate was $10 \mathrm{~mL}$ $\div 0.15 \mathrm{~mL}=67$; therefore the expected maximum amplification factor was 67 . When recombinant hGH was spiked at a concentration below the detection limit of the Immulite assay $(<0.05 \mathrm{ng} / \mathrm{mL})$ the particle sequestration increased the concentration to

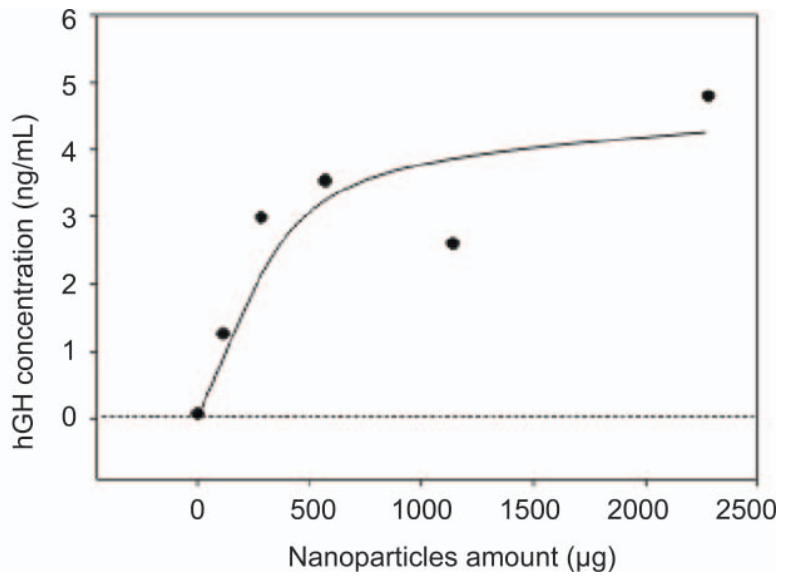

(a)

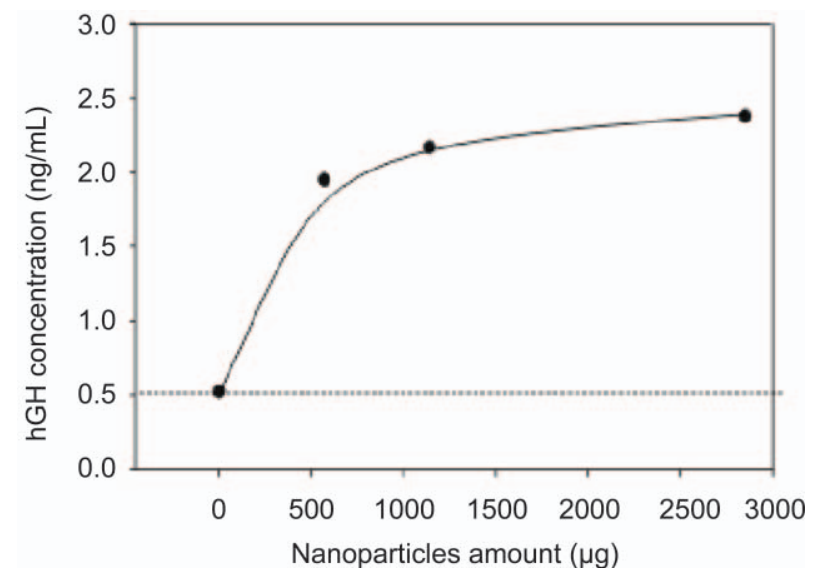

(b)

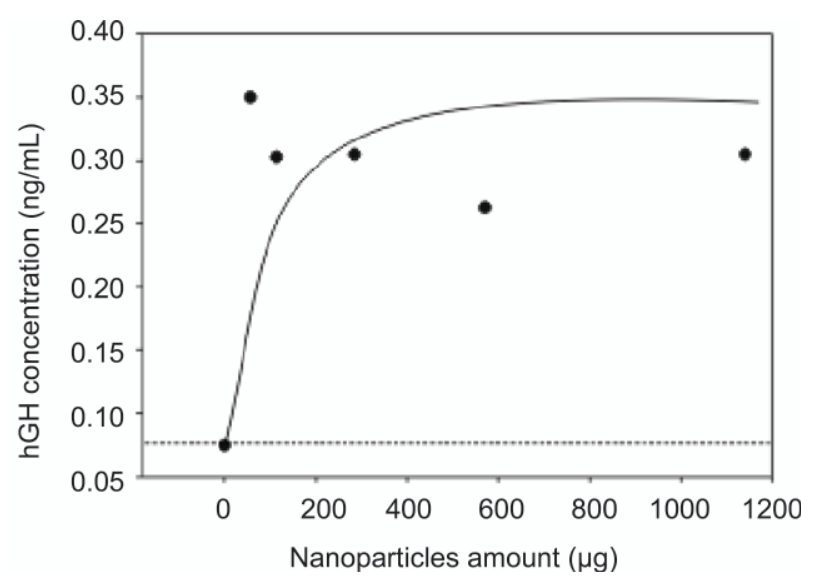

(c)

Figure 13 Particle dose response for capture of hGH. (a) Recombinant hGH was spiked in Surine and increasing amounts of particles were incubated with the analyte containing solution. The plateau is reached at about $600 \mu \mathrm{g}$. (b) Recombinant hGH was spiked in human urine and increasing amounts of particles were added to the solution. The plateau was reached at about $600 \mu \mathrm{g}$. (c) Cadaveric hGH was spiked in human urine and recovered with particles 


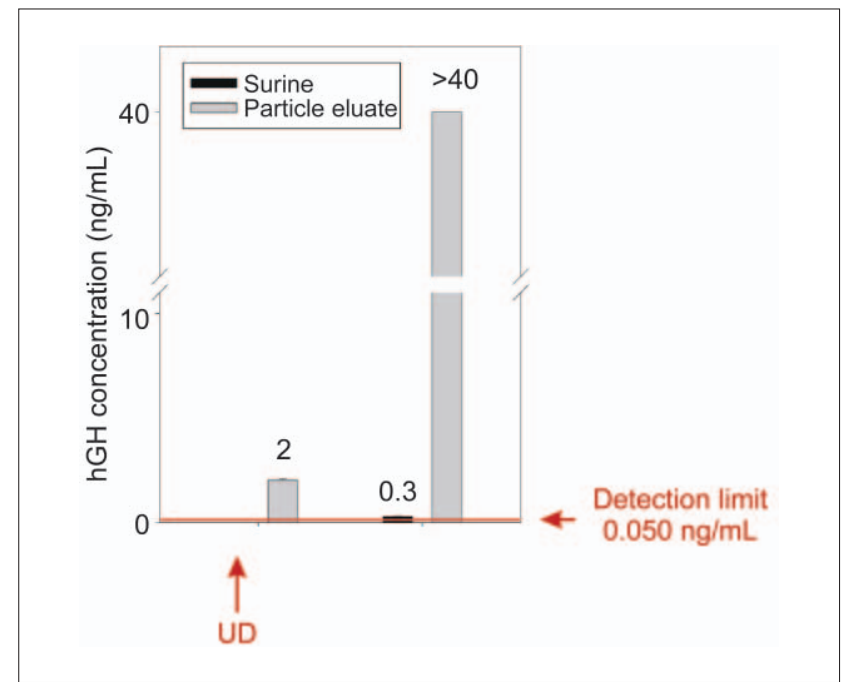

Figure 14 Effective amplification of urine hGH immunoassy sensitivity. Particles raised the concentration of recombinant hGH above the detection limit of the Immulite and greatly amplified the concentration of a solution in the linear range. UD means undetectable (below the detection limits of the Immulite assay)

a value of $1.21 \mathrm{ng} / \mathrm{mL}$. When the initial concentration in Surine was $170 \mathrm{pg} / \mathrm{mL}$, the concentration of hGH measured in the particle eluate was $6.50 \mathrm{ng} / \mathrm{mL}$ (concentration factor $=38$ ). Starting from an initial hGH concentration in Surine of $800 \mathrm{pg} / \mathrm{mL}$, the concentration measured by the Immulite assay exceeded the upper detection limit $(40 \mathrm{ng} / \mathrm{mL})$ of the assay (Fig. 15) (indicating a concentration factor greater than 50). All the supernatant fractions were completely depleted of hGH; this demonstrated that the particles captured all of the solution phase hGH in the entire volume of sample. As an additional quality check, the concentration of hGH in the particle eluate was found to be linearly dependent on the concentration of hGH in the starting solution of Surine, with coefficients of variation less than $5 \%$.

These data demonstrate that NIPAm/CB particles sequestered and concentrated hGH, a very low abundance biomarker in urine, raising the effective sensitivity from below the detection limit of a clinical immunoassay well into the linear range of the assay. A simple mathematical equation can predict the minimum concentration of hGH detectable by immunoassay following particle-based concentration and elution, knowing the sensitivity of the assay, the initial volume of urine, and the output volume of the elution:

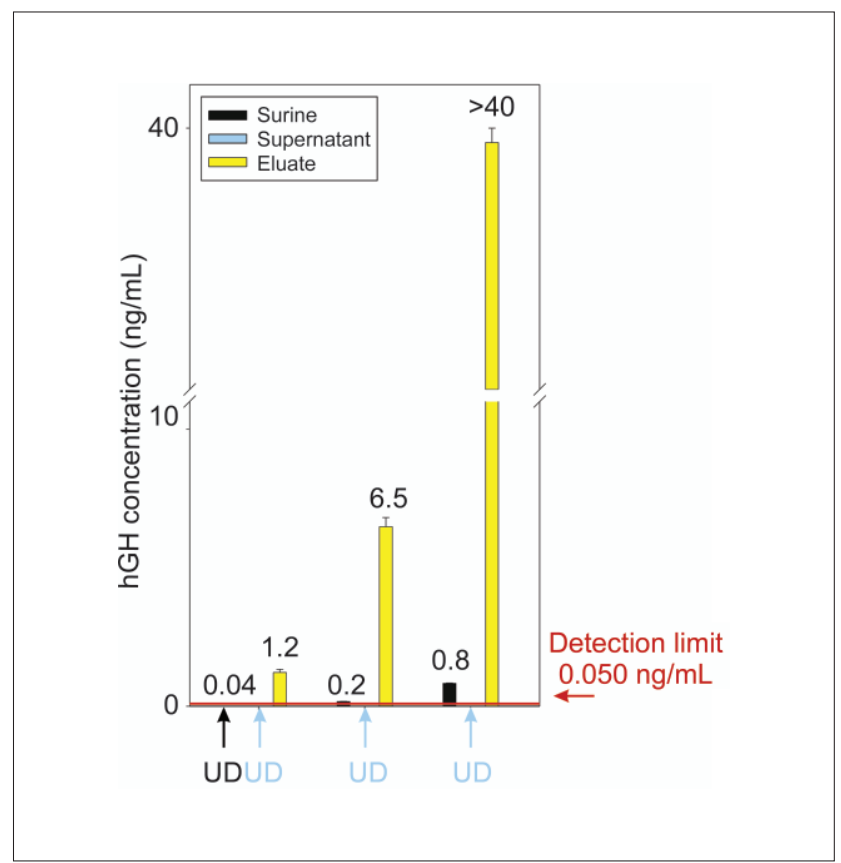

Figure 15 Effective amplification of urine hGH immunoassy sensitivity. Dose response study on recombinant hGH spiked in $10 \mathrm{ml}$ of Surine. Supernatants are depleted and hGH concentration in the particle eluate is linearly dependent on hGH concentration in Surine. UD means undetectable (below the detection limits of the Immulite assay)

$$
C_{\min }=T /(V / v)=T / c,
$$

where $C_{\min }$ is the minimum detectable concentration of hGH in urine, $T$ is the lowest limit of sensitivity of the immunoassay, $V$ is the starting volume of urine tested, $v$ is the output volume of the eluate, and $c=V / v$ is the concentration factor given by the ratio between the initial volume of urine and the volume of the eluate. Assuming that we have $100 \mathrm{~mL}$ of urine and the protein analytes captured in the particles can be eluted in the volume $v$ of $200 \mu \mathrm{L}$, the concentration factor $c$ is 500 and the sensitivity of the immunoassay $T$ is $50 \mathrm{pg} / \mathrm{mL}$; in this case $C_{\min }$, the minimum detectable concentration of hGH, will be $0.1 \mathrm{pg} / \mathrm{mL}$ with the immunoassay used in this study and with $100 \mathrm{~mL}$ of urine as a starting volume.

In order to test the ability of NIPAm/CB particles to collect and concentrate the endogenous hGH in human urine, we collected blood and urine from a healthy donor and tested both body fluids for hGH content. The hGH value in the blood was $1.34 \mathrm{ng} / \mathrm{mL}$, while the urine hGH value was below the detection limit of the Immulite assay $(<0.05 \mathrm{ng} / \mathrm{mL})$. NIPAm/ 
CB particles ( $3 \mathrm{~mL}, 17.1 \mathrm{mg})$ were incubated with 33 $\mathrm{mL}$ of urine $(\mathrm{pH}$ 6.5) and processed as previously described. Particle eluate $(100 \mu \mathrm{L})$ was diluted 1:2 with Sample Diluent and analyzed by Immulite assay. The hGH concentration in the particle eluate was $0.058 \mathrm{ng} / \mathrm{mL}$. We can therefore estimate the initial concentration of hGH in urine as $58 \mathrm{pg} / \mathrm{mL} /$ $(33 \mathrm{~mL} \div 0.1 \mathrm{~mL})=58 \mathrm{pg} / \mathrm{mL} \div 330=0.175 \mathrm{pg} / \mathrm{mL}$.

\section{Conclusions}

The ability to obtain a quantitative measurement of low molecular weight and low abundance proteins in human urine has important implications for clinical diagnosis and research, since many disease-related markers are low molecular weight peptides, proteins and metabolites that pass effectively through kidney glomerular filtration.

The normal range of hGH in serum is 1 to 10 $\mathrm{ng} / \mathrm{mL}$ but the urine concentration is around a thousand times lower, well below the detection limit (50 pg/mL) of most commercially available sensitive clinical hGH immunoassays. We have recently described the application of hydrogel nanoparticles for rapid biomarker concentration in blood [16]. In the present study we developed a new class of Cibacron Blue nanoparticles tailored for urine-based applications and used hGH as an example of a very low abundant biomarker whose routine urine measurement remains elusive because of its low concentration.

We synthesized Cibacron Blue bait-loaded hydrogel particles and successfully demonstrated their ability to capture, concentrate and preserve both recombinant and natural (cadaveric) hGH from model synthetic urine solutions, and from actual human urine. The optimized elution method we developed, based on strong base-containing buffers, was totally compatible with clinical grade immunological assays. The amount of hGH eluted from the particles was successfully measured by Immulite 1000 assay, which is routinely used for clinical serum analysis. Originally undetectable concentrations of hGH (below $0.05 \mathrm{ng} / \mathrm{mL}$ ) in a standard assay volume were dramatically increased, reaching a reliable detectable concentration $(2.0 \mathrm{ng} / \mathrm{mL})$.
These findings suggest that hydrogel particles functionalized with Cibacron Blue dye constitute a promising technology for the pre-processing of $\mathrm{hGH}$ in urine prior to its measurement by means of standard immunological techniques routinely used in clinical settings. The sensitivity in the linear range of a standard clinical assay for $100 \mathrm{~mL}$ of urine is 0.1 $\mathrm{pg} / \mathrm{mL}$. The physiological levels of hGH in human urine are poorly understood because it has not been readily possible to measure this analyte in the urine. In this study, urine from a healthy donor whose serum hGH concentration was $1.34 \mathrm{ng} / \mathrm{mL}$ was studied in order detect endogenous hGH. Starting from a volume of $33 \mathrm{~mL}$, the particle eluate had an $\mathrm{hGH}$ concentration of $58 \mathrm{pg} / \mathrm{mL}$, giving an estimated initial concentration of hGH in the urine of $0.175 \mathrm{pg} / \mathrm{mL}$.

The binding ability of the NIPAm/CB particles is not restricted to hGH; indeed we demonstrated that IL-8, a potential disease biomarker found in urine and blood, was successfully captured and concentrated by the particles. Hydrogel particles are highly stable in either dried or hydrated states. Thus, it would be feasible to preload the particles into a urine collection vessel so that clinically relevant small proteins could be immediately sequestered and preserved from the entire volume of collected urine and made available for analysis by clinical grade immunoassays. The nanotechnology described here appears to have the desired precision, accuracy, and sensitivity to support a large scale clinical study of urine candidate biomarkers.

\section{Acknowledgements}

The authors appreciate the generous support of Dr. Vikas Chandhoke and the College of Life Sciences at George Mason University. This work was partly supported by the Italian Istituto Superiore di Sanita' in the framework of the Italy/USA cooperation agreement between the U.S. Department of Health and Human Services, George Mason University and the Italian Ministry of Public Health. This work was partially supported by the U.S. Department of Energy grant number DE-FC52-04NA25455. The authors acknowledge stimulating discussions with Prof. Giovanni Muto. 


\section{References}

[1] Gonzalez-Buitrago, J. M.; Ferreira, L.; Lorenzo, I. Urinary proteomics. Clin. Chim. Acta 2007, 375, 49-56.

[2] Barratt, J.; Topham, P. Urine proteomics: The present and future of measuring urinary protein components in disease. CMAJ 2007, 177, 361-368.

[3] Pisitkun, T.; Johnstone, R.; Knepper, M. A. Discovery of urinary biomarkers. Mol. Cell. Proteomics 2006, 5, 1760 $-1771$.

[4] Kreunin, P.; Zhao, J.; Rosser, C.; Urquidi, V.; Lubman, D. M.; Goodison, S. Bladder cancer associated glycoprotein signatures revealed by urinary proteomic profiling. $J$. Proteome. Res. 2007, 6, 2631-2639.

[5] Moghimi, S. M.; Hunter, A. C.; Murray, J. C. Nanomedicine: Current status and future prospects. Faseb. J. 2005, 19, 311-330.

[6] Jain, K. K. Applications of nanobiotechnology in clinical diagnostics. Clin. Chem. 2007, 53, 2002-2009.

[7] Tanaka, T.; Sato, E.; Hirokawa, Y.; Hirotsu, S.; Peetermans, J. Critical kinetics of volume phase transition of gels. Phys. Rev. Lett. 1985, 55, 2455.

[8] Jones, C. D.; Lyon, L. A. Synthesis and characterization of multiresponsive core-shell microgels. Macromolecules 2000, 33, 8301-8306.

[9] Duracher, D.; Sauzedde, F.; Elaissari, A.; Perrin, A.; Pichot, $C$. Cationic amino-containing $n$-isopropylacrylamide-styrene copolymer latex particles: 1-Particle size and morphology vs polymerization process. Colloid. Polym. Sci.1998, 276, 219-231.

[10] Suzuki, A. and Tanaka, T. Phase transition in polymer gels induced by visible light. Nature 1990, 346, 345347.

[11] Tanaka, T.; Nishio, I.; Sun, S. -T.; Ueno-Nishio, S. Collapse of gels in an electric field. Science.1982, 218, 467-469.

[12] Hoffman, A. S. Hydrogels for biomedical applications. Adv. Drug Deliv. Rev. 2002, 54, 3-12.

[13] Liu, J.; Pelton, R.; Hrymak, A. N. Properties of poly ( $n$-isopropylacrylamide)-grafted colloidal silica. J. Colloid Interf. Sci. 2000, 227, 408-411.

[14] Cavalieri, F.; Chiessi, E.; Villa, R.; Vigano, L.; Zaffaroni, N.; Telling, M. F.; Paradossi, G. Novel PVA-based hydrogel microparticles for doxorubicin delivery. Biomacromolecules 2008, 9, 1967-1973.

[15] Zhang, X. Z.; Jo Lewis, P.; Chu, C. C. Fabrication and characterization of a smart drug delivery system: Microsphere in hydrogel. Biomaterials 2005, 26, 32993309.

[16] Luchini, A.; Geho, D. H.; Bishop, B.; Tran, D.; Xia, C.; Dufour, R. L.; Jones, C. D.; Espina, V.; Patanarut, A.; Zhou, W. et al. Smart hydrogel particles: Biomarker harvesting: One-step affinity purification, size exclusion, and protection against degradation. Nano Lett. 2008, 8, 350-361.

[17] Tuncel, A.; Ozdemir, A. Thermally reversible VPBANIPAM copolymer gels for nucleotide adsorption. J. Biomater. Sci. Polym. Ed. 2000, 11, 817-831.

[18] Ivanov, A. E.; Galaev, I. Y.; Mattiasson, B. Interaction of sugars, polysaccharides and cells with boronatecontaining copolymers: From solution to polymer brushes. J. Mol. Recognit. 2006, 19, 322-331.

[19] Popii, V.; Baumann, G. Laboratory measurement of growth hormone. Clin. Chim. Acta. 2004, 350, 1-16.

[20] Bidlingmaier, M.; Strasburger, C. J. Growth hormone assays: Current methodologies and their limitations. Pituitary 2007, 10, 115-119.

[21] Saugy, M.; Robinson, N.; Saudan, C.; Baume, N.; Avois, L.; Mangin, P. Human growth hormone doping in sport. Br. J. Sports Med. 2006, 40 Suppl 1, i35-39.

[22] Ehrnborg, C.; Rosen, T. Physiological and pharmacological basis for the ergogenic effects of growth hormone in elite sports. Asian J. Androl. 2008, 10, 373383.

[23] Barroso, O.; Mazzoni, I.; Rabin, O. Hormone abuse in sports: The antidoping perspective. Asian J. Androl. 2008, 10, 391-402.

[24] Rigamonti, A. E.; Cella, S. G.; Marazzi, N.; Di Luigi, L.; Sartorio, A.; Muller, E. E. Growth hormone abuse: Methods of detection. Trends Endocrinol. Metab. 2005, 16, 160-166.

[25] Albini, C. H.; Sotos, J.; Sherman, B.; Johanson, A.; Celniker, A.; Hopwood, N.; Quattrin, T.; Mills, B. J.; Macgillivray, M. H. Diagnostic significance of urinary growth hormone measurements in children with growth failure: Correlation between serum and urine growth hormone. Pediatr. Res. 1991, 29, 619-622.

[26] Hourd, P.; Edwards, R. Current methods for the measurement of growth hormone in urine. Clin. Endocrinol. (Oxf) 1994, 40, 155-170.

[27] Butt, D. A.; Sochett, E. B. Urinary growth hormone: A screening test for growth hormone sufficiency. Clin. 
Endocrinol. (Oxf) 1997, 47, 447-454.

[28] Saugy, M.; Cardis, C.; Schweizer, C.; Veuthey, J. L.; Rivier, L. Detection of human growth hormone doping in urine: Out of competition tests are necessary. J. Chromatogr. B Biomed. Appl. 1996, 687, 201-211.

[29] Denizli, A. ; Piskin, E. Dye-ligand affinity systems. J. Biochem. Bioph. Meth. 2001, 49, 391-416.

[30] Wakui, H.; Kobayashi, R.; Itoh, H.; Imai, H.; Nakamoto, Y.; Miura, A. B. High-yield purification of the complexforming glycoprotein in urine from normal and abnormal subjects. Clin. Chem. 1989, 35, 577-581.

[31] Sereikaite, J.; Bumelis, V. A. Examination of dye-protein interaction by gel-permeation chromatography. Biomed. Chromatogr. 2006, 20, 195-199.

[32] Sutkeviciute, I.; Sereikaite, J.; Bumelis, V. A. Analysis of cibacron Blue F3G-A interaction with therapeutic proteins by MALDI-TOF mass spectrometry. Biomed. Chromatogr. 2008, 22, 1001-1007.

[33] Lee, H. L.; Eom, H. S.; Yun, T.; Kim, H. J.; Park, W. S.; Nam, B. H.; Moon-Woo, S.; Lee, D. H.; Kong, S. Y. Serum and urine levels of interleukin-8 in patients with non-Hodgkin's lymphoma. Cytokine 2008, 43, 71-75.

[34] Huang, G.; Gao, J.; Hu, Z.; St John, J. V.; Ponder, B. C.; Moro, D. Controlled drug release from hydrogel nanoparticle networks. J. Control. Release 2004, 94, 303 -311 .

[35] Pecora, R. Dynamic light scattering: Applications of photo correlation spectroscopy; Springer: 1985.

[36] Jin, S. H.; Lee, Y. Y.; Kang, H. Y. Methyl-betacyclodextrin, a specific cholesterol-binding agent, inhibits melanogenesis in human melanocytes through activation of ERK. Arch. Dermatol. Res. 2008, 300, 451-454.

[37] Cai, W.; Yao, X.; Shao, X.; Pan, Z. Bimodal complexations of steroids with cyclodextrins by a flexible docking algorithm. J. Incl. Phenom. Macrocycl. Chem. 2005, 51, 41-51.

[38] Borst, C.; Holzgrabe, U. Enantioseparation of dopa and related compounds by cyclodextrin-modified microemulsion electrokinetic chromatography. J. Chromatogr. A 2008, 1204, 191-196.

[39 Ugurel, S.; Rappl, G.; Tilgen, W.; Reinhold, U. Increased serum concentration of angiogenic factors in malignant melanoma patients correlates with tumor progression and survival. J. Clin. Oncol. 2001, 19, 577-583.

[40] Xie, K. Interleukin-8 and human cancer biology. Cytokine Growth Factor Rev. 2001, 12, 375-391.

[41] Ren, Y.; Poon, R. T.; Tsui, H. T.; Chen, W. H.; Li, Z.; Lau, C.; Yu, W. C.; Fan, S. T. Interleukin-8 serum levels in patients with hepatocellular carcinoma: Correlations with clinicopathological features and prognosis. Clin. Cancer Res. 2003, 9, 5996-6001.

[42] Gall, M. A.; Hougaard, P.; Borch-Johnsen, K.; Parving, H. H. Risk factors for development of incipient and overt diabetic nephropathy in patients with non-insulin dependent diabetes mellitus: Prospective, observational study. BMJ 1997, 314, 783-788.

[43] Carroll, M. F.; Temte, J. L. Proteinuria in adults: A diagnostic approach. Am. Fam. Physician 2000, 62, 1333 -1340 . 